\title{
Índice de Mobilidade Urbana Sustentável em Goiânia como ferramenta para políticas públicas
}

\author{
Sustainable Urban Mobility Index \\ in Goiânia as a tool for public policies
}

Ivanilde Maria de Rezende Abdala Antônio Pasqualetto

\begin{abstract}
Resumo
Abordam-se conceitos de mobilidade e de mobilidade urbana sustentável e suas interações com o ambiente urbano. Buscando melhorias na movimentação das pessoas e serviços, em especial o uso dos veículos, conduz a investigações para a mobilidade satisfatória nos espaços públicos e qualidade de vida da população. Assim, pesquisadores discutem o assunto, na busca de índices para medir parâmetros. Neste, objetivou-se calcular o Índice de Mobilidade Urbana Sustentável - Imus para a cidade de Goiânia com levantamento dos dados em 2011 e 2012, adotando a metodologia de Costa (2008) . 0 cálculo efetivou-se no se gundo semestre de 2012, explanando que, para solucionar o problema do trânsito e transporte, necessitava-se vinculá-lo à política urbana. Assim, recomenda que o Imus seja uma ferramenta para auxiliar e contribuir na proposição, formulação, implantação e monitoramento de políticas públicas relacionadas à mobilidade urbana sustentável de Goiânia.
\end{abstract}

Palavras-chave: índice de mobilidade; cidades; políticas públicas; sustentabilidade.

\section{Abstract}

This paper approaches concepts of mobility and Sustainable Urban Mobility and their interactions with the urban environment. Seeking improvements in the movement of persons and services, in particular in the use of vehicles, it leads to investigations aiming at satisfactory mobility in public spaces and at the quality of life of the population. Thus, researchers discuss the subject in search of indices to measure parameters. In this study, the aim was to calculate the Sustainable Urban Mobility Index (SUMI) to the city of Goiânia (Central-Western Brazil) with data survey in 2011 and 2012, adopting the methodology proposed by Costa (2008). The calculation was made in the second half of 2012 and revealed that, to solve the problem of traffic and transport, it is necessary to associate the index with the urban policy. Therefore, it is recommended that SIMU is used as a tool to assist in and contribute to the proposition, formulation, implementation, and monitoring of public policies related to the sustainable urban mobility of Goiânia.

Keywords: mobility index; cities; public policy; sustainability. 


\section{Introdução}

A concentração de pessoas nas cidades, notadamente nas grandes e em regiões metropolitanas e a consequente necessidade de mobilidade ligada ao aumento do uso dos veículos automotores têm resultado baixa qualidade de vida.

Os problemas referentes à mobilidade são agravados por investimentos insuficientes e às vezes inadequados, e também pela ausência de políticas públicas que priorizem os modos coletivos e os não motorizados de forma a tornar mais equânime à apropriação do espaço urbano pelos diversos modos de transporte. Dessa forma, ficam comprometidos os deslocamentos da população no atendimento e realização de suas necessidades diárias, principalmente da parcela da população de baixa renda, dependentes do transporte público e sem espaços nas vias para a utilização segura de modos não motorizados.

No deslocamento da população, o transporte público ou coletivo de qualidade é fator preponderante e influi na qualidade de vida urbana, sendo também fator direcionador do seu desenvolvimento econômico e social. Assim sendo, é necessário um equacionamento adequado do transporte em geral em conjunto com suas políticas, em especial a do uso do solo interligado ao transporte.

Como mobilidade e transportes estão intrinsecamente interligados, na busca de solucionar os seus problemas, estudos apontam a ações que levam à mobilidade urbana sustentável, e, dentre os artifícios necessários, deve-se tratar a questão do transporte e trânsito vinculada à política urbana. Para tanto, é imperativo a provisão de facilidades para responder à demanda por milhares de deslocamentos diários, por diferentes modos e motivos.

$\mathrm{Na}$ busca de melhor planejamento que controle com mais austeridade o uso do espaço urbano, tem-se direcionado a estudos e investigações em direção à mobilidade sustentável. Dessa maneira, pesquisadores têm discutido o assunto buscando estabelecer parâmetros, identificar fatores que impactam a mobilidade e obter soluções para ela, dentre as quais, índices que possam medir a condição de vida da população assim como de sua mobilidade. Do mesmo modo

[...] estudos para estabelecer parâmetros para o desenvolvimento de metodologias de monitoramento da Mobilidade Urbana, buscando subsidiar a definição de políticas públicas. (Centro de Gestão e Estudos Estratégicos - CGE, 2009)

Um importante instrumento para elaboração de diagnósticos é o Índice de Mobilidade Urbana Sustentável - Imus, desenvolvido por Costa (2008). Esse índice, formado por um conjunto de 87 indicadores, foi desenvolvido com a proposta de oferecer uma metodologia capaz de avaliar quantitativamente e qualitativamente vários aspectos pertinentes à mobilidade, incluindo os cenários essenciais - social, econômico e ambiental.

Assim sendo, objetivou-se avaliar, à luz da metodologia citada, o Imus para Goiânia. 


\section{Mobilidade urbana sustentável}

0 termo "Mobilidade Urbana Sustentável" teve seu desdobramento e desenrolar inicialmente como "desenvolvimento sustentável", surgido por meio do relatório Nosso Futuro Comum (Our Common Future) ou Relatório de Brundtland - pela World Commission on Environment and Development - WCED em 1987. Cita-se desenvolvimento sustentável, aquele que "atende às necessidades do presente sem comprometer a possibilidade de as gerações futuras atenderem suas próprias necessidades" (Brasil, 2006, p. 48).

Pode-se considerar "Desenvolvimento Sustentável" como um termo amplo que implica desenvolvimento continuado e sustentabilidade como um termo vasto que envolve várias atividades humanas e de maneira simplificada é prover o melhor para as pessoas e para o meio ambiente tanto no presente como para o futuro. Portanto, sustentabilidade pode ser definida como a que tem por finalidade observar e praticar os aspectos ambientais, sociais, e econômicos e buscar alternativas para sustentar a vida no Planeta sem prejudicar a qualidade de vida no futuro.

Boareto $(2008$, p. 152) afirma que

[...] conceitos e formas de avaliação sobre o desenvolvimento sustentável das cidades são imprecisos e requerem ainda muita discussão, principalmente nos países em desenvolvimento, (...) com a consequente repercussão sobre a política de mobilidade urbana.

Em relação à mobilidade urbana, Rodri- gues da Silva et al. (2008) afirmam que a in- corporação das premissas de sustentabili- dade ambiental, econômica e social no planeja- mento do desenvolvimento urbano é relativamente recente no Brasil, principalmente no que se refere ao planejamento da mobilidade. Macedo et al. (2012) alegam que, estimulado por políticas públicas, os planos diretores só recentemente incorporaram a noção de mobilidade sustentável em seu texto e incluíram a mobilidade das pessoas com deficiência, dado à crescente importância e gravidade dos problemas de acessibilidade e circulação dentre as questões urbanas.

O conceito de mobilidade urbana é ex- tenso e também envolve várias definições complementares sendo difícil definir separadamente, como também o é mobilidade urbana e mobilidade urbana sustentável. Conceituar mobilidade urbana reporta a relações que interagem no espaço urbano juntamente com outros conceitos, devido à multidisciplinariedade envolvida. Dessa forma, é comum associar o conceito de mobilidade ao transporte, sobretudo aos modos motorizados, e também praticamente apenas a circulação de automóveis e ao uso de transporte coletivo.

0 padrão de mobilidade urbana no Brasil vem se modificando com o aumento acelerado da taxa de motorização, pois os segmentos de menor renda também estão tendo acesso ao veículo privado. A tendência é continuar crescendo e cada vez mais pessoas poderão ter acesso a esse bem, ainda estimulado por políticas de incentivo pois, como afirma Boareto (2008, p. 145) "a maioria dos formuladores de políticas urbanas considera 0 automóvel como desejo natural e destino final de todas as pessoas".

Influenciam na mobilidade urbana fatores como as dimensões do espaço urbano, a 
complexidade das atividades nele desenvolvidas, a disponibilidade de serviços de transporte e questões da população principalmente a renda e faixa etária (Brasil, 2006). Para Magagnin et al. (2008) o crescimento das cidades influencia e é influenciado pelos meios de transporte disponíveis à sua população, e

[..] a maneira como se dá o processo de circulação urbana interfere diretamente na demanda por transportes nas áreas destinadas a estacionamento, nos congestionamentos, etc.

Macêdo et al. (2006, p. 3) acreditam que um dos maiores problemas em relação às soluções da mobilidade se dá pelo tratamento privilegiado recebido pelo transporte motorizado individual, e pelo descaso aos demais modos e serviços, sinalizando, assim, para o estímulo ao uso do carro. Para a melhoria, é necessário haver maior percepção e interação entre os vários sistemas de deslocamentos como a pé, de bicicleta, transporte coletivo, transporte motorizado individual, ou seja, contemplar todos os modos e redes de transporte como:

[...] rede de transporte público-coletivo e individual; rede de transporte individual motorizado; rede de transporte individual não-motorizado - calçada para pedestres e ciclovias, rede de paradas, terminais e pontos de transferência e a rede de infraestruturas que suporta todos os modos. (Ibid.)

Conforme Costa (2008), o contexto das cidades e a busca pelo desenvolvimento sustentável têm provocado a revisão das formas de compreender e planejar o meio urbano. Nas discussões ocorridas durante esse processo, as quais envolvem planejadores, administradores públicos, comunidade acadêmica e sociedade em geral, alguns aspectos têm merecido destaque. Entre eles, as dificuldades impostas à circulação de pessoas e bens, causada pela falta de integração entre o planejamento urbano e de transportes, e o declínio da qualidade ambiental das cidades em função de seus sistemas de mobilidade.

Lopes (2010) enfatiza a importância da consideração de efeitos espaciais e pelas relações de transporte e uso do solo, de forma dinâmica e integrada, no estudo da mobilidade urbana em busca do desenvolvimento urbano sustentável. Portanto, problemas enfrentados pelas cidades com crescimento rápido ocorrem muitas vezes devido à falta de políticas públicas mais direcionadas às pessoas e que possa orientar o crescimento espacial de forma sustentável e com qualidade de vida. Assim, afirma Boareto (2008) ser necessário que os governos considerem a mobilidade urbana como resultado de uma política pública. Segundo Magagnin e Rodrigues da Silva (2008), para tal são necessários instrumentos efetivos de controle e monitoramento da mobilidade urbana, bem como de políticas mais sustentáveis destinadas a orientar o crescimento e o ordenamento espacial.

Macêdo et al. (2012) apontam que o tema desenvolvimento sustentável, de natureza pluri e interdisciplinar, tem mobilizado setores da comunidade acadêmica no sentido de desenvolver índices, a partir da fusão de vários indicadores, na tentativa de sintetizar em um único parâmetro as condições de mobilidade nas cidades e por meio deles diagnosticar os principais problemas e acompanhar o resultado de implantação de políticas públicas com vistas ao desenvolvimento sustentável. Nesse 
sentido, os indicadores de mobilidade fornecem informações necessárias e indispensáveis ao planejamento urbano.

\section{Indicadores e Índices da Mobilidade Sustentável}

Comum às cidades, especialmente as maiores, aparecerem relacionadas ao caos e crescimento desordenado, como também o trânsito e transportes. Visando à melhoria das condições da cidade e da qualidade de vida das pessoas propostas são feitas na criação de um índice que qualifique a mobilidade urbana e avalie seu grau de sustentabilidade. Com isso, na obtenção de índices, as análises por meio de indicadores têm alcançado maior peso nas metodologias utilizadas para obter informações de caráter técnico e científico, permitindo que a informação seja mais facilmente utilizável por tomadores de decisão, gestores, políticos, grupos de interesse e pelo público em geral, como apontado em Magagnin (2008); Lopes (2010); Machado (2010); Miranda (2010); Mancini, (2011); Da Assunção, (2012)).

Para Gudmundsson (2011), os impactos ambientais dos transportes necessitam ser mensurados e que por indicadores obtém-se melhor representação das preocupações de sustentabilidade na tomada de decisões de transporte, em todas as áreas, em todos os níveis, também pela necessidade de se reduzir a complexidade da informação. A avaliação por indicadores contém variáveis que representam um fenômeno de interesse, podem ser medidas e preenchidas com dados, como também informar uma variedade de funções de avaliação, e que muitas vezes são repetidas e re gularmente reportáveis, e ainda são sempre construídas e selecionadas.

Gudmundsson (2011, p. 10) também afirma que:

[...] um indicador é uma variável, com base em medições, que representa com a maior precisão possível e necessária um fenômeno de interesse

e que

[...] um indicador de sustentabilidade ambiental nos transportes é uma variável, com base em medições, que representa impactos potenciais ou reais sobre o meio ambiente ou fatores que podem causar tais impactos, devido ao transporte, com a maior precisão possível e necessária.

No Brasil, ainda não existem métodos comprovados de avaliação que qualifiquem corretamente a mobilidade e seu grau de sustentabilidade e que apontem sugestões para compreender e posteriormente melhorar a condição existente.

Procurando suprir essa deficiência, foi criado o Índice de Mobilidade Urbana Sustentável - Imus, que, conforme Costa (2008), é uma ferramenta para avaliação da mobilidade urbana sustentável, ou seja, uma ferramenta de apoio à tomada de decisão dos gestores públicos nos processos de formulação, implantação e monitoramento de políticas públicas com vistas à promoção da mobilidade urbana. E que é "capaz de revelar as condições atuais e medir os impactos de medidas e estratégias que visam à mobilidade sustentável" (Macêdo et al., 2012, p. 1769). 


\section{Imus - Índice de Mobilidade Urbana Sustentável}

0 Imus, formulado por Costa (2008), se constitui em uma ferramenta para monitoração da mobilidade urbana sustentável e avaliação do impacto de políticas públicas, estruturado a partir de conceitos identificados em 11 capitais de estados brasileiros entre 2006 e 2007, e entre as cidades selecionadas estava Goiânia/GO (CGE, 2009).

Esse índice é composto por nove domínios, distribuídos em 37 temas e 87 indicadores. Em sua composição, apresentam-se questões tradicionais e também as relacionadas à mobilidade sustentável, e, devido a essa diversificação, adapta-se a qualquer realidade urbana. A avaliação dos indicadores é feita através de um sistema de pesos que os qualifica de forma individual e também em grupo, podendo assim reconhecer a contribuição relativa de cada ele mento para todo o sistema (Miranda, 2010).

0 Imus é uma ferramenta que se propõe a ser utilizado para a avaliação e monitoração da mobilidade urbana considerado de fácil compreensão e manipulação. Permite avaliar condições atuais e os impactos de medidas e estratégias, visando à mobilidade urbana sustentável. Propõe também ser um instrumento de contribuição e subsídios para a formulação de políticas públicas.

Os vários aspectos, conforme o Guia de Indicadores (Costa, 2008), são expostos nos domínios.

Além da hierarquia de critérios, o Imus se utiliza de um sistema de pesos que são definidos, além da qualificação de forma individual, também em nível setorial, para os temas em relação a cada uma das dimensões da sustentabilidade: social, econômica e ambiental; e em nível global. Dessa forma, a cada indicador é associado um peso que permite avaliar a contribuição do indicador, para o resultado do Imus. Segundo descrito por Plaza e Rodrigues da Silva (2010, pp. 1769-1770),

[...] para o cálculo do Imus o produto dos pesos associados a cada indicador pelos seus respectivos escores é combinado segundo uma lógica de compensação entre critérios, ou seja, um indicador com valor baixo pode ser compensado por outro com valor alto, de forma a evidenciar a contribuição global e setorial dos mesmos para o resultado final do Imus. 0 resultado final, ou escore normalizado, sempre se situa entre zero e um, valores que correspondem, respectivamente, à pior e à melhor condição possível.

As tabelas e detalhes sobre o cálculo do índice e o processo de normalização são expostos no Guia de Indicadores do Imus, parte integrante do trabalho de Costa (2008).

\section{Guia de Indicadores de Mobilidade}

Para cada um dos indicadores, as informações apresentam-se organizadas, conforme a estrutura (Tabela 1) definida por Costa (2008).

$$
A \text { - Definição }
$$

Descrição de cada Indicador do Imus.

\section{$B$ - Fontes de Dados}

Fontes dos dados necessários para o cálculo de cada indicador específico.

\section{C - Método de Cálculo}

Resumo do desenvolvimento do indicador, de acordo com as etapas contidas no Guia de 
Tabela 1 - Domínio, tema e indicador do Índice de Mobilidade Urbana - Imus

\begin{tabular}{c|c}
\hline Domínio & Domínio conforme estrutura do Imus \\
\hline Tema & Tema conforme estrutura do Imus \\
\hline Indicador & Identificação do Indicador \\
\hline
\end{tabular}

Indicadores do Imus, contendo fórmulas e ferramentas utilizadas.

$$
\text { D-Score }
$$

Resultado obtido para o indicador, não normalizado.

\section{E-Normalização}

Resultado normalizado em escala de 0 a 1 de acordo com a tabela de normalização indicada no Guia de Indicadores do Imus.

\section{F-Pesos}

Os pesos para os critérios obtidos segundo a avaliação de um painel de especialistas.

No caso do indicador ter sido calculado com base em dados numéricos e necessitar ser normalizado para valores entre 0,00 e 1,00, a escala de avaliação deve ser usada como referência para definição dos valores mínimo e máximo necessários para obtenção do escore normalizado, ou mesmo para a associação direta do escore obtido para o indicador, conforme indicado no método de cálculo.

No caso de avaliação, sem que seja feito o cálculo efetivo do indicador, a avaliação, com base na escala proposta, deve ser feita por técnico ou gestor com conhecimento sobre os dados e da cidade em questão. Os resultados obtidos por meio da avaliação substituem, portanto, os valores dos indicadores que não puderam ser obtidos pelo método principal.

Os indicadores estão classificados em qualitativos, quantitativos e mistos uma vez que a grande maioria está contida na quantitativa conforme Figura 1.

Figura 1 - Indicadores do Imus conforme tipologia

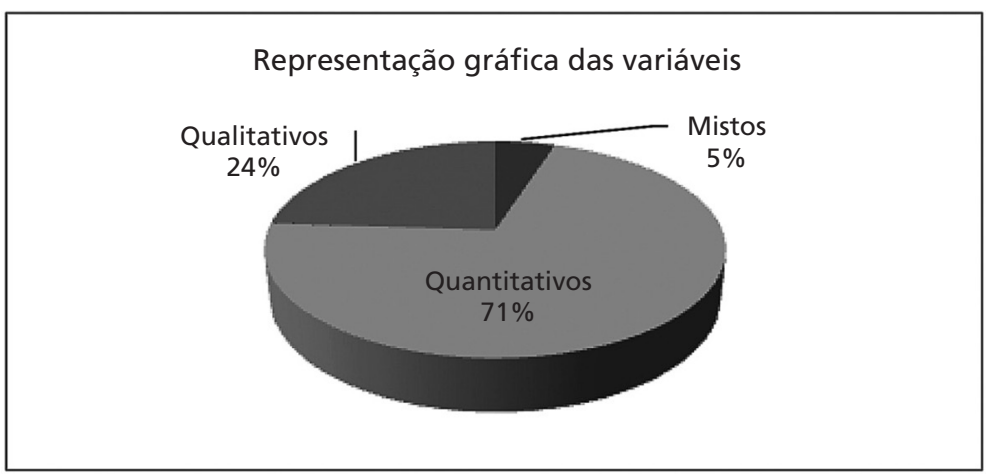

Fonte: Guia de Indicadores (Costa, 2008). 
Baseado na Figura 1 e segundo a interpretação de Costa (2008), verifica-se que há predomínio dos indicadores quantitativos na estrutura do Imus, o que representa $71 \%$ do conjunto total de indicadores. Indicadores que exigem, para seu desenvolvimento, o levantamento de dados quantitativos por meio de bases de dados ou outras fontes de informação, além do desenvolvimento de métodos de cálculo para obtenção de seu escore. Os demais indicadores dos tipos qualitativos e mistos representaram, respectivamente, $24 \%$ e $5 \%$ do conjunto total.

$\mathrm{Na}$ busca de minimizar e solucionar os problemas relacionados à mobilidade urbana em geral e em especial ao transporte público e ao trânsito, tem-se estudado vários índices de Imus, como em Machado (2010), para levantar e medir os aspectos pertinentes à mobilidade urbana. Assim, entre os vários estudos de índices, o Imus se aprofundou e, para validá-lo, ele foi aplicado e calculado em algumas cidades, ou seja, foi efetivado em várias cidades, entre elas, têm-se: São Carlos/SP, Costa, (2008); Curitiba/PR, Miranda (2010); Anápolis/GO, Morais, (2012); Uberlândia/MG, Da Assunção, (2012).

Com os resultados dos índices e com as intervenções necessárias, são capazes de sofrerem ações visando a sua melhoria, sendo calculado e finalizado, neste ano de 2013, para Goiânia/GO.

\section{Aplicação do índice em Goiânia}

\section{Considerações no cálculo do Imus de Goiânia}

Para o cálculo do índice, é necessária a cole- ta de uma grande quantidade de dados que, no caso da cidade em questão, envolveu uma busca contínua em várias secretarias municipais e estaduais, além de outras fontes. Alguns dados foram obtidos através do cruzamento de informações de mais de um banco de dados, como por exemplo, da Celg Distribuição S.A. Celg D, com os dados da Secretaria Municipal de Planejamento de Goiânia - Seplam, atualmente Secretaria Municipal de Desenvolvimento Urbano Sustentável - Semdus e processados no Departamento de Geoprocessamento dessa secretaria.

Além da adequação de alguns indicadores para a obtenção dos dados a serem utilizados no cálculo de um índice mais realista, assim como a revisão de outros, é necessário e de grande importância ter boa atualização dos dados utilizados, ter acompanhamento continuado, e certa regularidade. Também que essa atualização seja convenientemente estipulada em determinado número de anos, como por exemplo, a cada dois anos, qual seja, no meio e ao final de cada administração. Desse modo, 
para o cálculo do índice de Goiânia, na maioria de seus indicadores foi concretizado com os princípios recomendados.

\section{0 Índice de Mobilidade Urbana Sustentável em Goiânia}

Na cidade de Goiânia, o cálculo do Imus foi realizado para a quase totalidade dos indicadores, ou seja, de um total de 87, que compõem sua estrutura, foram calculados 85 . Para alguns dados, foi feito atualização com explicação e ponderação desses dados, e, em alguns casos, apresentado sugestão de meIhoria do indicador.

Os resultados dos indicadores obtidos conforme a estrutura do Imus ou adaptados para a cidade de Goiânia é mostrada na Tabela 2 , onde expõe-se o escore ou resultado de cada indicador.

0 resultado tanto do Imus Global como o setorial é mostrado na Tabela 3. Com os indicadores levantados e o índice calculado, o valor do Imus Global encontrado para Goiânia foi de 0,659 , isto é, em torno da média de $66 \%$, um valor positivo. Dessa maneira comprova que na cidade há vários aspectos da mobilidade que seguem os princípios da sustentabilidade, porém muitos necessitam serem melhorados para alcançar uma mobilidade satisfatória.

Analisando as dimensões integrantes do Imus, tem-se que na social há uma predominância sobre as demais. Porém na dimensão ambiental, mesmo Goiânia tendo um total em áreas verdes consideráveis com 32,61 m²/habitante, superior a $25 \mathrm{~m}^{2}$ por habitante que é o valor sugerido pelo Imus para atingir o máximo de 1,00, isso sendo computado somente as áreas de proteção permanente, sem contar as árvores, praças e ilhas do sistema viário, teve pontuação menor que as outras. Comprova-se assim, que há vários aspectos ambientais que necessitam ser aprimorados além do verde da cidade.

Em relação aos escores obtidos (ver Tabela 2), observa-se que 55,295\% têm índices superiores a 0,70; 15,295\% têm valores entre 0,50 e 0,69 também com valor positivo, e que somente $29,41 \%$ apresentam-se entre baixa e baixíssima pontuação $(0,00$ a 0,49$)$, isso em relação à linha intermediária. Assim sendo, observa-se que, de uma maneira geral, tem-se que $70,59 \%$ estão da linha intermediária para cima e $29,41 \%$ com baixa pontuação.

Desse modo, os resultados obtidos para o município de Goiânia indicam que tanto os indicadores de escores com valores superiores a 0,50 quanto os com valores inferiores a 0,49 poderão ser utilizados como referência nos planos de governo, fornecendo elementos para a proposição de políticas e estratégias governamentais e indicando a necessidade de priorizar ações em direção à melhoria da mobilidade. Em relação aos indicadores com dados positivos, poderão ser monitorados para que não percam suas características como também possam receber incentivos para continuar se aperfeiçoando e interagindo com os demais. Quanto aos indicadores com dados inferiores, deverão ser aplicadas medidas pautadas nas políticas públicas como correção, adequação, ajustamento e melhoria dos espaços públicos já construídos, e os ainda por construir deverão ser edificados conforme leis e normas favoráveis ao progresso da mobilidade. Enfim, em todos os casos potencializar as decisões políticas, adequando-as para 0 avanço rumo à mobilidade satisfatória. 


\section{Tabela 2 - Desempenho dos indicadores no cálculo do Imus para a cidade de Goiânia}

\begin{tabular}{|c|c|c|c|c|c|c|c|c|c|c|}
\hline \multirow{2}{*}{ 吕 } & \multirow{2}{*}{ Peso } & \multicolumn{3}{|c|}{ Dimensões } & \multirow{2}{*}{ Temas } & \multirow{2}{*}{ Peso } & \multirow{2}{*}{ ID } & \multirow{2}{*}{ Indicadores } & \multirow{2}{*}{ Peso } & \multirow{2}{*}{ Escore } \\
\hline & & $\mathrm{S}$ & E & A & & & & & & \\
\hline \multirow{10}{*}{ 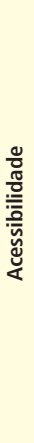 } & \multirow{10}{*}{$\frac{\infty}{\circ}$} & 0,38 & 0,36 & 0,26 & \multirow{3}{*}{ Acessibilidade aos sistemas de transporte } & & 1.1.1 & Acessibilidade ao transporte público & 0,33 & 0,93 \\
\hline & & & & & & & 1.1.2 & Transporte público para pessoas com necessidades especiais & 0,33 & 1,00 \\
\hline & & & & & & & 1.1.3 & Despesas com transporte & 0,33 & 0,59 \\
\hline & & 0,40 & 0,32 & 0,27 & \multirow{5}{*}{ Acessibilidade universal } & & 1.2 .1 & Travessias adaptadas para pessoas com necessidades especiais & 0,20 & 0,10 \\
\hline & & & & & & & 1.2 .2 & Acessibilidade aos espaços abertos & 0,20 & 0,71 \\
\hline & & & & & & & 1.2 .3 & $\begin{array}{l}\text { Vagas de estacionamento para pessoas com necessidades } \\
\text { especiais }\end{array}$ & 0,20 & 1,00 \\
\hline & & & & & & & 1.2 .4 & Acessibilidade a edifícios públicos & 0,20 & 0,37 \\
\hline & & & & & & & 1.2 .5 & Acessibilidade aos serviços essenciais & 0,20 & 1,00 \\
\hline & & 0,38 & 0,30 & 0,32 & Barreiras físicas & 0,22 & 1.3.1 & Fragmentação urbana & 1,00 & 0,00 \\
\hline & & 0,46 & 0,28 & 0,27 & $\begin{array}{l}\text { Legislação para pessoas com necessidades } \\
\text { especiais }\end{array}$ & 0,21 & 1.4 .1 & Ações para acessibilidade universal & 1,00 & 1,00 \\
\hline \multirow{6}{*}{ 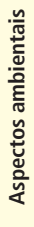 } & \multirow{6}{*}{$\stackrel{m}{\frac{m}{\sigma}}$} & 0,29 & 0,28 & 0,43 & \multirow{6}{*}{ Controle de impactos no meio ambiente } & \multirow{4}{*}{0,52} & 2.1 .1 & Emissões de CO & 0,25 & 0,00 \\
\hline & & & & & & & 2.1 .2 & Emissões de $\mathrm{CO}_{2}$ & 0,25 & 1,00 \\
\hline & & & & & & & 2.1 .3 & População exposta ao ruído de tráfego & 0,25 & 0,76 \\
\hline & & & & & & & 2.1 .4 & Estudos de impacto ambiental & 0,25 & 1,00 \\
\hline & & \multirow{2}{*}{0,26} & \multirow{2}{*}{0,32} & \multirow{2}{*}{0,42} & & \multirow{2}{*}{0,48} & 2.2 .1 & Consumo de combustivel & 0,50 & 0,83 \\
\hline & & & & & & & 2.2 .2 & Uso de energia limpa e combustiveis alternativos & 0,50 & 0,00 \\
\hline \multirow{5}{*}{ 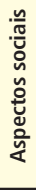 } & & 0,40 & 0,31 & 0,29 & Apoio ao cidadão & 0,21 & 3.1 .1 & Informação disponível ao cidadão & 1,00 & 0,75 \\
\hline & & 0,45 & 0,30 & 0,25 & Inclusão social & 0,20 & 3.2 .1 & Equidade vertical (renda) & 1,00 & 0,58 \\
\hline & $\stackrel{0}{=}$ & 0,39 & 0,30 & 0,31 & Educação e cidadania & 0,19 & 3.3 .1 & Educação para o desenvolvimento sustentável & 1,00 & 1,00 \\
\hline & & 0,41 & 0,27 & 0,32 & Participação popular & 0,19 & 3.4 .1 & Participação na tomada de decisão & 1,00 & 1,00 \\
\hline & & 0,35 & 0,30 & 0,35 & Qualidade de vida & 0,21 & 3.5 .1 & Qualidade de vida & 1,00 & 1,00 \\
\hline & & 0,33 & 0,34 & 0,32 & 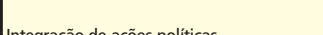 & & 4.1.1 & Integração entre níveis de governo & 0,50 & 0,75 \\
\hline$\tilde{\delta}$ & & & & & 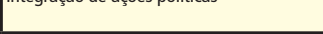 & 0,34 & 4.1 .2 & Parcerias público-privadas & 0,50 & 0,50 \\
\hline 䓂 & & 0,33 & 0,40 & 0,27 & & & 4.2 .1 & Captação de recurso & 0,25 & 0,56 \\
\hline 气 & $\bar{\sigma}$ & & & & Conta & & 4.2 .2 & Investimentos em sistemas de transporte & 0,25 & 0,75 \\
\hline 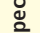 & & & & & & & 4.2 .3 & Distribuição dos recursos (coletivo $\mathrm{X}$ privado) & 0,25 & 1,00 \\
\hline 争 & & & & & & & 4.2 .4 & Distribuição dos recursos (motorizados $\mathrm{X}$ não motorizados) & 0,25 & 0,25 \\
\hline & & 0,34 & 0,33 & 0,32 & Política de mobilidade urbana & 0,34 & 4.3 .1 & Política de mobilidade urbana & 1,00 & 1,00 \\
\hline & & 0,28 & 0,41 & 0,31 & & & 5.1 .1 & Densidade e conectividade da rede viária & 0,25 & 1,00 \\
\hline$\stackrel{2}{z}$ & & & & & Provisão e manutenção de infraestrutura & & 5.1 .2 & Vias pavimentadas & 0,25 & 0,97 \\
\hline$\ddot{y}$ & 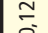 & & & & de transportes & & 5.1 .3 & Despesas com manutenção da infraestrutura & 0,25 & 0,50 \\
\hline$\underline{\underline{E}}$ & & & & & & & 5.1 .4 & Sinalização viária & 0,25 & 0,80 \\
\hline & & 0,33 & 0,35 & 0,33 & Distribuição da infraestrutura de transportes & 0,54 & 5.2 .1 & Vias para transporte coletivo & 1,00 & 0,66 \\
\hline & & 0,32 & 0,29 & 0,39 & & & 6.1 .1 & Extensão e conectividade de ciclovias & 0,33 & 0,25 \\
\hline 气ั & & & & & Transporte cicloviário & 0,31 & 6.1 .2 & Frotas de bicicleta & 0,33 & 0,05 \\
\hline$\stackrel{\sqrt[n]{2}}{\sqrt[n]{2}}$ & & & & & & & 6.1 .3 & Estacionamento de bicicletas & 0,33 & 0,64 \\
\hline 范 & & 0,33 & 0,28 & 0,39 & Declecamen & 0.30 & 6.2 .1 & Vias para pedestres & 0,50 & 0,25 \\
\hline E & $\overline{0}$ & & & & Desicentictios a pe & 0,04 & 6.2 .2 & Vias com calçada & 0,50 & 0,94 \\
\hline$\stackrel{n}{n}$ & & 0,28 & 0,32 & 0,40 & & & 6.3 .1 & Distância de viagem & 0,00 & *vazio \\
\hline$\frac{}{0}$ & & & & & 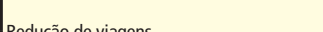 & 0 & 6.3 .2 & Tempo de viagem & 0,00 & *vazio \\
\hline & & & & & 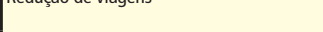 & 0 & 6.3 .3 & Número de viagens & 0,50 & 0,85 \\
\hline & & & & & & & 6.3 .4 & Ações para redução do tráfego motorizado & 0,50 & 0,25 \\
\hline
\end{tabular}




\begin{tabular}{|c|c|c|c|c|c|c|c|c|c|c|}
\hline \multirow{2}{*}{$\begin{array}{l}\text { 侃 } \\
\text { हूँ }\end{array}$} & \multirow{2}{*}{ Peso } & \multicolumn{3}{|c|}{ Dimensões } & \multirow{2}{*}{ Temas } & \multirow{2}{*}{ Peso } & \multirow{2}{*}{ ID } & \multirow{2}{*}{ Indicadores } & \multirow{2}{*}{ Peso } & \multirow{2}{*}{ Escore } \\
\hline & & $s$ & $\mathrm{E}$ & A & & & & & & \\
\hline \multirow{18}{*}{ 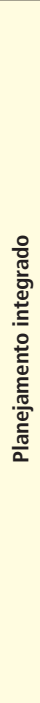 } & \multirow{18}{*}{$\frac{\infty}{\circ}$} & \multirow{2}{*}{0,31} & \multirow{2}{*}{0,37} & \multirow{2}{*}{0,32} & \multirow{2}{*}{ Captação de gestores } & \multirow{2}{*}{0,12} & 7.1 .1 & Nivel de formação de técnicos e gestores & 0,50 & 0,74 \\
\hline & & & & & & & 7.1 .2 & Capacitação de técnicos e gestores & 0,50 & 1,00 \\
\hline & & 0,35 & 0,30 & 0,35 & Áreas centrais de interesse histórico & 0,11 & 7.2.1 & Vitalidade do centro & 1,00 & 0,54 \\
\hline & & 0,31 & 0,34 & 0,35 & Integração regional & 0,12 & 7.3.1 & Consórcios intermunicipais & 1,00 & 1,00 \\
\hline & & 0,38 & 0,32 & 0,31 & Transparência do processo de planejamento & 0,12 & 7.4 .1 & Transparência e responsabilidade & 1,00 & 1,00 \\
\hline & & 0,31 & 0,32 & 0,38 & \multirow{5}{*}{$\begin{array}{l}\text { Planejamento e controle do uso } \\
\text { e ocupação do solo }\end{array}$} & \multirow{5}{*}{0,14} & 7.5 .1 & Vazios urbanos & 0,20 & 0,92 \\
\hline & & & & & & & 7.5.2 & Crescimento urbano & 0,20 & 0,30 \\
\hline & & & & & & & 7.5 .3 & Densidade populacional & 0,20 & 0,00 \\
\hline & & & & & & & 7.5.4 & Índice de uso misto & 0,20 & 1,00 \\
\hline & & & & & & & 7.5 .5 & Ocupações irregulares & 0,20 & 0,99 \\
\hline & & 0,32 & 0,35 & 0,33 & \multirow{2}{*}{ Planejamento estratégico e integrado } & Do: & 7.6 .1 & Planejamento urbano, ambiental e de transporte integrado & 0,50 & 0,50 \\
\hline & & & & & & & 7.6 .2 & Efetivação e continuidade de ações & 0,50 & 1,00 \\
\hline & & 0,31 & 0,39 & 0,30 & & & 7.7.1 & Parques e áreas verdes & 0,33 & 1,00 \\
\hline & & & & & Planejamento da infraestrutura urbana & 0,13 & 7.7.2 & Equipamentos urbanos (escolas) & 0,33 & 0,54 \\
\hline & & & & & & & 7.7 .3 & Equipamentos urbanos (postos de saúde) & 0,33 & 0,02 \\
\hline & & 0,31 & 0,35 & 0,35 & & & 7.8 .1 & Plano diretor & 0,33 & 1,00 \\
\hline & & & & & Plano diretor e legislação urbanisttica & 0,12 & 7.8 .2 & Legislação urbanistica & 0,33 & 1,00 \\
\hline & & & & & & & 7.8 .3 & Cumprimento da legislação urbanística & 0,33 & 1,00 \\
\hline & & 0,37 & 0,38 & 0,26 & & & 8.1 .1 & Acidentes de trânsito & 0,33 & 0,94 \\
\hline$\cong$ & & & & & Acidentes de trânsito & 0,21 & 8.1 .2 & Acidentes com pedestres e ciclista & 0,33 & 0,92 \\
\hline 号 & & & & & & & 8.1 .3 & Prevenção de acidentes & 0,33 & 0,01 \\
\hline 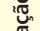 & & 0,39 & 0,31 & 0,30 & Educação para o trânsito & 0,19 & 8.2.1 & Educação para o trânsito & 1,00 & 0,42 \\
\hline בั & $\div$ & 0,29 & 0,35 & 0,36 & I & (1) & 8.3 .1 & Congestionamento & 0,50 & 1,00 \\
\hline בै & & & & & Fluidez e circulaçao & {$[0,19$} & 8.3 .2 & Velocidade média do tráfego & 0,50 & 1,00 \\
\hline ब্ֶ & & 0,34 & 0,33 & 0,33 & Operação e fiscalização de trânsito & 0,20 & 8.4.1 & Violação das leis de trânsito & 1,00 & 1,00 \\
\hline$\stackrel{\pi}{=}$ & & 0,32 & 0,31 & 0,36 & & & 8.5 .1 & Índice de motorização & 0,50 & 0,00 \\
\hline & & & & & & & 8.5.2 & Taxa de ocupação de veículos & 0,50 & 0,13 \\
\hline & & 0,35 & 0,33 & 0,32 & & & 9.1 .1 & Extensão da rede do transporte público & 0,13 & 0,06 \\
\hline & & & & & & & 9.1.2 & Frequência de atendimento do transporte público & 0,13 & 0,61 \\
\hline & & & & & & & 9.1.3 & Pontualidade & 0,13 & 0,85 \\
\hline & & & & & Disponibilidade e qualidade & 073 & 9.1 .4 & Velocidade média do transporte público & 0,13 & 0,29 \\
\hline & & & & & do transporte público & & 9.1.5 & Idade média da frota de transporte público & 0,13 & 1,00 \\
\hline స్ & & & & & & & 9.1.6 & Índice de passageiros por quilômetro & 0,13 & 0,03 \\
\hline$\equiv$ & & & & & & & 9.1.7 & Passageiros transportados anualmente & 0,13 & 0,75 \\
\hline$\frac{t}{0}$ & & & & & & & 9.1.8 & Satisfação do usuário com o serviço de transporte público & 0,13 & 0,27 \\
\hline $\bar{n}$ & $\cong$ & 0,31 & 0,34 & 0,34 & & & 9.2 .1 & Diversidade de modos de transporte & 0,33 & 0,75 \\
\hline 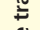 & $0^{\circ}$ & & & & Diversificacãão modal & 0,18 & 9.2 .2 & Transporte coletivo $\mathrm{X}$ transporte individual & 0,33 & 0,00 \\
\hline$\overline{\tilde{c}}$ & & & & & & & 9.2 .3 & Modos não motorizados X modos motorizados & 0,33 & 0,00 \\
\hline$\xi_{0}$ & & 0,34 & 0,35 & 0,31 & Regulação e fiscalizacão & & 9.3 .1 & Contratos e licitaç̃ôs & 0,50 & 1,00 \\
\hline$\frac{n}{n}$ & & & & & do transporte público & 0,18 & 9.3 .2 & Transporte coletivo & 0,50 & 1,00 \\
\hline & & 0,37 & 0,33 & 0,30 & L & & 9.4.1 & Terminais intermodais & 0,50 & 0,00 \\
\hline & & & & & & 0,22 & 9.4 .2 & Integração do transporte público & 0,50 & 1,00 \\
\hline & & 0,38 & 0,37 & 0,35 & & & 9.5 .1 & Descontos e gratuidades & 0,33 & 0,67 \\
\hline & & & & & Política tarifária & 0,19 & 9.5 .2 & Tarifas de transporte & 0,33 & 0,00 \\
\hline & & & & & & & 9.5.3 & Subsídios públicos & 0,33 & 0,50 \\
\hline
\end{tabular}

* Peso zero (0) pela inexistência de dados, redistribuído para os demais indicadores do mesmo tema. Fonte: Costa (2008). 
Tabela 3 - Resultado do Imus Global e setorial de Goiânia

\begin{tabular}{c|c}
\hline Dimensão do Imus & Valor normalizado \\
\hline Imus Global & 0,659 \\
Imus Social & 0,224 \\
Imus Econômica & 0,219 \\
Imus Ambiental & 0,216 \\
\hline
\end{tabular}

Fonte: Adaptado de Costa (2008).

\section{Desempenho do Imus em Goiânia}

No desempenho do Imus da cidade, avalia-se o desempenho individual de cada um dos domínios e também de cada um dos indicadores.

\section{Desempenho dos domínios}

Analisando individualmente, como na Figura 2, o resultado obtido em cada domínio particular do Imus da cidade, permite uma avaliação separada e preliminar. Isso se dá através do cálculo individualizado de cada domínio, considerando os demais domínios com seus indicadores como não calculados, ou seja, o resultado obtido para os demais domínios como vazios. Portanto, o resultado obtido para o Imus Global, dessa maneira, corresponde somente aos grupos de domínios isolados, e assim há uma comparação entre cada área distinta em relação às demais.

Figura 2 - Desempenho dos domínios

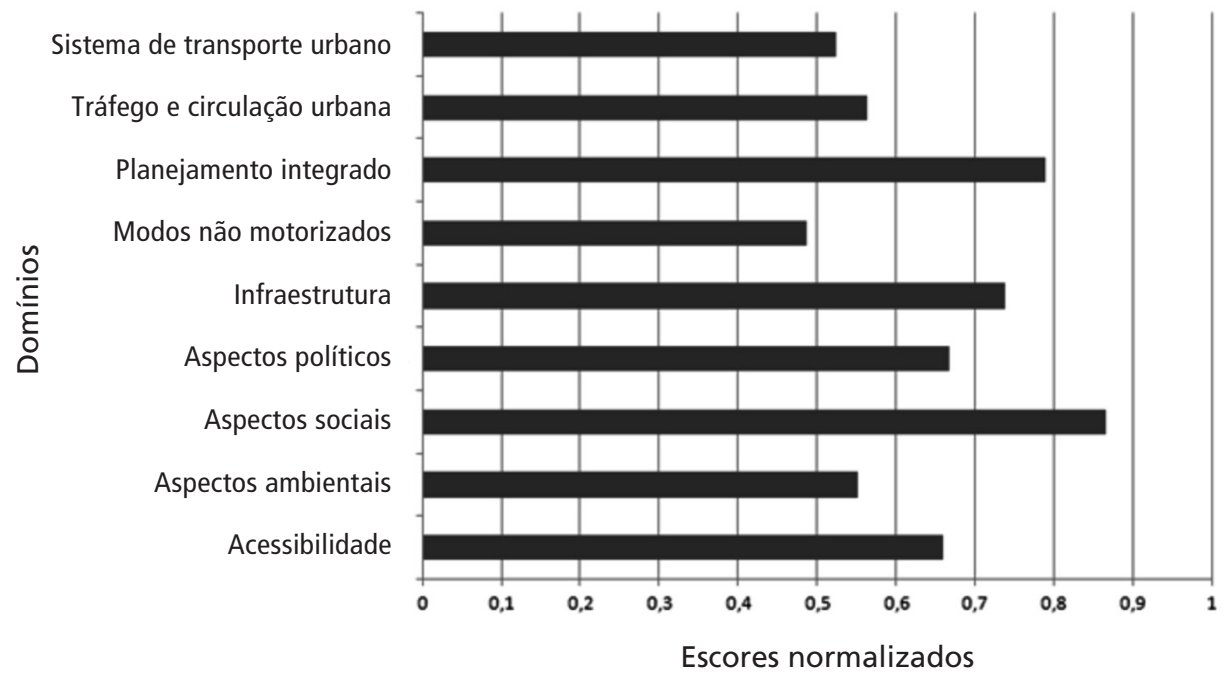


Entre os domínios, o de Modos Não Motorizados, o único que não obteve nenhum indicador com valor máximo, foi o que teve o menor desempenho entre todos, ou seja, abaixo de 0,50 especificamente um Imus Global médio de 0,4861 e o domínio de melhor desempenho é o de Aspectos Sociais com o valor do Imus Global médio de 0,866.

\section{Desempenho dos indicadores}

Com os 85 indicadores calculados (Tabela 2) e uma classificação mais geral, têm-se 28 indicadores (32,94\%) com escore máximo, ou seja, $(1,00)$ e $09(10,59 \%)$ escore zero (mínimo). Considerando valores com índices superiores a 0,70, têm-se 47 indicadores (55,295\%) e ainda com o escore incluindo 0,50 acima resultou em 60 indicadores $(70,59 \%)$, ou seja, indicadores com resultados entre médios, bons e excelentes e abaixo de $0,50(0,01$ a 0,49) há 16 indicadores $(18,82 \%)$.

Indicadores de alto desempenho

Os indicadores com alto desempenho obtiveram escore 1,00, desse modo, somente necessitam atuar para preservar suas boas características, assim como interagir com os demais para uma melhoria Global.

Após, têm-se os indicadores com escores normalizados e valores entre 0,75 e 0,99, são 17 indicadores (20\%), não são excelentes, porém são bons, indica que também necessitam preservar suas características positivas, além de intervenções para atingir excelentes ou melhores resultados.
Já os indicadores que têm valores com escores normalizados entre 0,50 e 0,74 são em número de 15 ou $17,65 \%$ do total calculado e necessitam de maior atenção do poder público uns com intervenções mais profundas e outros com média intensidade para atuação e consequente melhoria dos mesmos. Pode-se exemplificar aqui, o Indicador Acessibilidade aos Espaços Abertos com o escore 0,71 do domínio Acessibilidade. Apesar de, mesmo apresentando resultados superiores a 0,50, necessitam de intervenções, investimentos e ações com mais rigor devido ao fato de ter entre seus indicadores alguns com valores baixos. Devem ser realizadas intervenções observando mais detalhadamente as especificidades de cada indicador, para a melhoria da mobilidade da cidade, mesmo que determinados indicadores não apresentem desempenhos baixos.

Como o grupo de indicadores citados com alto desempenho reflete o bom desempenho dos respectivos domínios, em Goiânia, com o maior Imus Global médio têm-se o domínio Aspectos Sociais e em ordem decrescente o de Planejamento Integrado, após o de Infraestrutura e posterior Aspectos Políticos e Acessibilidade. No domínio Acessibilidade, um domínio expressivo com Imus Global médio de 0,67 , há indicadores com escores excelentes, assim como outros entre ruins, péssimos e também um (1) com valor ínfimo (zero). Por tanto, com os resultados, vê-se que é um domínio com valor médio, porém com alguns indicadores com baixo desempenho que necessitam muito de intervenções compatíveis com a sua impor tância para melhorar a mobilidade e acessibilidade das pessoas na cidade. 
Indicadores de baixo desempenho

Os indicadores com baixo desempenho foram aqui classificados em ruins, péssimos e ínfimos. Os ruins são os que possuem escore entre 0,25 e 0,49 e correspondem ao total de 09 e percentual de $10,59 \%$.

Os indicadores classificados como péssimos possuem escore entre 0,01 e 0,24, corresponde ao total de 07 e percentual de $8,23 \%$.

Os indicadores apontados como ínfimos são os que possuem o escore 0,00 , em número de 09 e correspondem ao percentual de 10,59\% também.

Portanto, indicadores de baixo desempenho, ou seja, os com menores escores são consequentemente os que têm maiores deficiências e necessitam muito de intervenções e ações mais diretas com políticas mais austeras para a melhoria da mobilidade urbana. Pode-se exemplificar aqui, os indicadores Travessias adaptadas para pessoas com necessidades especiais com escore de 0,10 e Acessibilidade a edifícios públicos, com escore de 0,37 , ambos do domínio Acessibilidade. Como já citado, por ter valores muito baixos necessitam de políticas e ações intervencionistas profundas e certamente mais urgentes, para minimizar os problemas relacionados à mobilidade urbana de Goiânia, em especial neste item, à acessibilidade da cidade.

Os indicadores com escore ínfimo ou zero são : Fragmentação urbana, do domínio Acessibilidade; Emissões de $\mathrm{CO}$ e Uso de energia limpa e combustíveis alternativos, ambos do domínio Aspectos Ambientais; Densidade populacional urbana, do domínio Planejamento Integrado; Índice de Motorização, do domínio Tráfego e Circulação Urbana; Transporte coletivo $\mathrm{X}$ transporte individual, Modos não motorizados $\mathrm{X}$ modos motorizados, Terminais intermodais e Tarifas de transporte; estes últimos do domínio Sistemas de Transporte Urbano. Portanto, muito se tem a fazer para que a cidade obtenha um índice maior e mais condizente com a qualidade de vida da qual Goiânia é conhecida, e consequentemente uma mobilidade com nível satisfatório.

\section{Imus como ferramenta de comparação de escores}

Mesmo não sendo realizado o cálculo de todos os indicadores, é possível simular a obtenção de valores utilizando dados como se esses indicadores que não foram calculados, sejam avaliados com valores apresentados como intermediários máximos e mínimos, como indicado na Tabela 4.

0 Imus proporciona uma análise mais detalhada das condições de mobilidade e, portanto, também permite identificar os pontos mais deficitários para que, assim, possa mais diretamente indicar a melhor direção e atuação para o desempenho de seus indicadores e em sequência da cidade. 
Tabela 4 - Simulações para indicadores não calculados

\begin{tabular}{l|c|c|c|c}
\hline $\begin{array}{c}\text { Dimensão } \\
\text { do IMUS }\end{array}$ & $\begin{array}{c}\text { Valor } \\
\text { normalizado* }\end{array}$ & $\begin{array}{c}\text { Escores } \\
\text { estimados** }\end{array}$ & $\begin{array}{c}\text { Escores } \\
\text { máximos 1*** }\end{array}$ & $\begin{array}{c}\text { Escores } \\
\text { mínimos 2**** }\end{array}$ \\
\hline Imus Global & 0,659 & 0,658 & 0,668 & 0,649 \\
Imus Social & 0,224 & 0,224 & 0,226 & 0,221 \\
Imus Econômica & 0,219 & 0,219 & 0,222 & 0,216 \\
Imus Ambiental & 0,216 & 0,216 & 0,220 & 0,212 \\
\hline
\end{tabular}

Fonte: Adaptado de Costa (2008)

* Obtido pelo cálculo dos 85 indicadores disponíveis.

** Obtido pelo cálculo dos 85 indicadores disponíveis e dos 2 indicadores (não disponíveis) com valores estimados intermediários.

*** Obtido pelo cálculo dos 85 indicadores disponíveis e dos 2 indicadores (não disponíveis) com valores máximos (iguais a 1,00).

**** Obtido pelo cálculo dos 85 indicadores disponíveis e dos 2 indicadores (não disponíveis) com valores mínimos (iguais a 0,00).

\section{Comparação do Imus entre cidades com o cálculo efetivado}

0 cálculo do Imus foi efetivado em várias cidades brasileiras para se medir o nível de mobilidade em cada uma e também para que se possa validar e contribuir para o aperfeiçoamento do índice. Aqui são mostrados os resultados obtidos em algumas cidades onde se percebe que as dimensões em cada uma delas apresenta de forma diferente ou peculiar como visto na Tabela 5.

Nota-se que nas cidades com os respectivos índices calculados, a variação das dimensões aconteceu de maneira diferenciada, isso em decorrência dos valores dos indicadores de cada uma. Na dimensão social, em todas as cidades comparadas, foi superior tanto em relação à econômica como na ambiental, porém a variação de valor entre elas difere em amplitude de uma cidade para a outra. Desse modo, na maioria a econômica apresenta com valor superior à ambiental, porém em Uberlândia esta última foi superior à econômica. Essa variação sucede em decorrência das condições de seu desenvolvimento, assim como às características específicas de cada cidade, às escoIhas políticas, como também da atuação dos técnicos e gestores, e ainda da atuação responsável e vigilante da população em geral, que cobrando interferem na melhoria e crescimento da respectiva cidade.

Em relação às ações nas cidades e à mobilidade urbana sustentável, para que haja um melhor desenvolvimento, deve haver uma constante relação entre os transportes com 0 uso do solo, com as edificações e seus usos, as instalações e equipamentos, ou seja, atividades que produzem ou atraem viagens. Reduzindo o uso do transporte individual e consequentemente aumentando o transporte coletivo, meIhora-se a mobilidade e exigem-se medidas de qualificação do transporte público e restrições 
Tabela 5 - Resultados do Imus Global e setorial em várias cidades e Goiânia

\begin{tabular}{l|c|c|c|c|c}
\hline \multirow{2}{*}{$\begin{array}{c}\text { Dimensão } \\
\text { do Imus }\end{array}$} & Curitiba & Uberlândia & Goiânia & São Carlos & Anápolis \\
\cline { 2 - 6 } & 0,754 & 0,717 & 0,659 & 0,568 & 0,419 \\
Imus Global & 0,255 & 0,243 & 0,224 & 0,192 & 0,142 \\
Imus Social & 0,250 & 0,236 & 0,219 & 0,191 & 0,141 \\
Imus Econômica & 0,249 & 0,238 & 0,216 & 0,186 & 0,136 \\
\hline
\end{tabular}

Fonte: Adaptado de Costa (2008).

impostas ao transporte privado. Isso visando à melhoria da cidade, pois, sistemas de mobilidade ineficientes pioram as desigualdades, socioespacial no urbano, exigindo, por parte dos governantes, a adoção de políticas públicas com o objetivo de se construir uma mobilidade urbana sustentável do ponto de vista econômico, social e ambiental.

\section{Ações de melhoria da mobilidade urbana em Goiânia}

Na resolução dos problemas em relação à mobilidade, é imperativo se aliar à Política Nacional de Mobilidade Urbana na busca de soluções que priorizem principalmente os modais de transporte coletivos e os não motorizados. Sendo assim, uma das medidas necessárias para a melhoria da mobilidade é a elaboração do Plano de Mobilidade Urbana, onde, na Lei $n$. 12.587, de 3/1/2012, política acima citada, foi estipulado o prazo máximo de 3 anos a partir de sua vigência, ou seja, até 3/1/2015. Sem o Plano, a cidade terá impedimentos para receber recursos orçamentários federais destinados à mobilidade urbana (Brasil, 2012).
Logo, para a mobilidade de Goiânia com qualidade de vida, é necessário, além da elaboração do referido Plano, perseguir os desafios estratégicos do transporte público como ser viço essencial e seu financiamento. $E$, paralelamente, a cobrança das externalidades negativas, provocadas pelo uso do automóvel e da motocicleta, deve ser feita extensamente, para compensar as desvantagens causadas para o transporte público, os pedestres e os usuários de bicicleta. Também inverter as prioridades de uso do espaço e de escolha modal.

Uma das questões que agrava os problemas de mobilidade para a população é a alta dependência do transporte rodoviário associada com a degradação das condições de trânsito, o que acarreta uma consequente perda de competitividade do transporte público urbano rodoviário em relação ao privado. Outro agravante é o transporte público coletivo urbano atender majoritariamente a pessoas de média e baixa renda no Brasil, direcionando assim a que o valor da tarifa desses serviços se torne um instrumento importante na formulação de políticas de inclusão social e também na gestão da mobilidade urbana. 
No cálculo do Imus de Goiânia ao conhecer os indicadores com maiores deficiências, ou seja, valores que necessitam de maiores intervenções, os gestores e o poder público poderão selecionar medidas para serem aplicadas no intuito de minimizar o nível de investimentos dos indicadores, aumentando, assim, a abrangência das ações. Referente ao indicador 9.5.2 Tarifas de Transporte, obteve-se valor (zero) devido ao aumento da tarifa ter sido superior ao índice inflacionário selecionado, atestando que o seu valor é fator importante para o cálculo do Imus.

Para o item 1.2.4 Acessibilidade a edifícios públicos, com a definição "Porcentagem de edifícios públicos adaptados para acesso e utilização de pessoas com necessidades especiais ou restrições de mobilidade", foi realizada uma extensa pesquisa para avaliar se os edifícios públicos atendem aos parâmetros de acessibilidade e segurança para pessoas com deficiência, conforme as normas e legislação vigentes (NBR 9050). Além da pesquisa realizada, foi feito um estudo de contribuição ao índice, e, quanto ao indicador, foi calculado conforme o proposto no Guia de Indicadores, porém o estudo propôs a sua modificação para uma melhor avaliação, por não concordar com o proposto no Imus (Macêdo et al., 2012), ou seja, por considerar outra proposta com aplicação mais realista e menos utopista. Por ser um indicador que afeta diretamente a liberdade de ir e vir das pessoas, especialmente as com deficiência e com mobilidade reduzida sem auxílio para a realização das atividades diárias, e apontado como sendo um indicador necessário a ser melhorado, deverá ser aplicado medidas de correção e adequação desses prédios como também a reforma ou implantação de novas calçadas, melhorando também aspectos ambientais.
Outro indicador do Imus de Goiânia que terá muito que ser aprimorado para que a mobilidade seja aperfeiçoada é o de Travessias adaptadas para pessoas com necessidades especiais, que obteve um escore baixíssimo, ou seja, de 0,10.

Um aspecto importante a ser considerado em relação aos problemas de mobilidade refere-se à gestão metropolitana dos serviços de transportes. Isso principalmente quando se observa a tendência de crescimento acelerado dos municípios periféricos em relação aos municípios núcleos dos grandes aglomerados urbanos, como é o caso de alguns municípios do entorno de Goiânia. Portanto, se não mudar as tendências atuais, o comércio futuro do transporte público não é promissor, a não ser que políticas favoráveis, incluindo restrições ao uso do automóvel, sejam implantadas. Entretanto, quando as políticas de incentivo ao uso de transporte público são escassas, estima-se que a maior parte dessas viagens será feita em motocicletas e automóveis, o que pode levar ao caos o trânsito nas regiões metropolitanas.

É fato que as políticas públicas de transporte e trânsito têm, ao longo da história, investido mais recursos no apoio ao deslocamento por automóveis, tornando precárias as condições de circulação a pé, em bicicleta ou em ônibus. Devido a esses fatos é urgente que as cidades se municiem de planos e políticas de mobilidade urbana em direção a ações sustentáveis e que também avaliem seus índices com certa regularidade, para então buscar acertar como e onde investir e assim melhorar a mobilidade de todas as pessoas. Todavia, uma das causas para o crescimento do transporte individual no Brasil são as políticas públicas de incentivos ou subsídios 
desbalanceados entre os diferentes modais, priorizando frequentemente o transporte por automóveis e motocicletas.

Contudo, na busca das soluções urbanas e da mobilidade urbana sustentável, é de suma importância buscar financiamentos. No Brasil, o principal órgão de financiamento do transporte público urbano é o BNDES, com financiamento de veículos e equipamentos para as empresas e também projetos de melhoria da infraestrutura para prefeituras e estados. Há os organismos de fomento internacionais, como o Banco Interamericano de Desenvolvimento (BID) e o Bird. Além das ações de repasse de recursos a fundo perdido, o governo federal possui linhas de financiamento para a mobilidade urbana por meio de um programa de financiamento de infraestrutura para a mobilidade urbana, o Programa de Infraestrutura para a Mobilidade Urbana (Pró-Mob).

Há também a Emenda Constitucional (EC) $n^{\circ} 33$ /2001, uma fonte de recursos para investimento no setor de transporte, tanto urbano como regional. Nela confere que os recursos arrecadados pela cobrança da Contribuição de Intervenção no Domínio Econômico (Cide) - relativa às atividades de importação ou comercialização de petróleo e seus derivados, de gás natural e seus derivados e álcool combustível - ficam vinculados a pagamento de subsídios a preços ou transporte dos combustíveis citados. Também o financiamento de projetos ambientais relacionados com a indústria do petróleo e do gás e a financiamento de programas de infraestrutura de transportes. Referente a essas fontes de recursos, para a melhoria do Imus de Goiânia, tem-se que os indicadores Emissões de $\mathrm{CO}$ e Uso de energia limpa e combustíveis alternativos do domínio
Aspectos Ambientais que obtiveram escore zero $(0,00)$ e que, portanto, estão entre as prioridades.

Pontuando a necessidade de uma atuação mais responsável em relação às políticas anteriormente aplicadas consta no PDIG de 1992, o PDIG 2000, que até 1950, Goiânia

[...] cresceu e se desenvolveu de acordo com as previsões do plano original, graças principalmente ao rigoroso controle exercido pelas autoridades administrativas do Município e do Estado.

E que, em seguida,

[...] experimentou cerca de 20 anos de crescimento excepcionalmente acelerado, que coincidiu com administrações desatentas quanto ao cumprimento das determinações do Plano Urbanístico.

Portanto, acredita-se que para gerir uma política "atenta" ou em conformidade ao Planejamento Urbano deve ser estabelecido um conjunto de decisões sobre o que e como deve ser feito para que a cidade possa superar seus defeitos funcionais e se organizar para sustentar os encargos resultantes da evolução prevista, como: promover, permitir ou proibir. Tanto nos estudos como na implantação contar também com a colaboração dos demais órgãos da municipalidade, buscando maior integração, bem como órgãos das esferas estadual e federal de governo. Assim como também envolver a população, ou seja, criar entre as pessoas maior consciência sobre os impactos negativos de determinadas ações e modos de vida que prejudicam a sustentabilidade.

Com a integração promover sugestões e expectativas da comunidade, através de suas entidades representativas, com consultas por 
meio de seminários e debates, e durante também no processo de execução. Igualmente pela Câmara Municipal de Goiânia, com palestras, debates e consultas populares sobre as expectativas da população para o futuro da cidade, fornecendo importantes subsídios, levados a discussão não só no processo de elaboração do Plano, mas também na implantação das ações. Isso durante os vários anos e as administrações consecutivas, em que é necessário que as leis sejam aplicadas e, quando revistas, façam-na com imparcialidade para o benefício da maioria da população e não em benefício de algumas classes empresariais ou dominantes. Necessário também formular o Plano de Mobilidade Urbana e assim ter acessos maiores a investimentos imprescindíveis à melhoria da Mobilidade Urbana em direção à sustentabilidade da cidade e em especial de todas as pessoas. E em conjunto, na sequência, rever e incentivar adaptações da estrutura urbana, visando estimular as viagens por modos sustentáveis, como também a seleção e a implantação de ações e políticas com a mesma finalidade, assim como capacitar técnicos e gestores para vencer os desafios.

Nas observâncias das ações para a mobilidade as estratégias do desenvolvimento urbano de Goiânia e consequentemente do seu ordenamento territorial, contidas em seu Plano Diretor atual (Goiânia, 2007), direcionam-se a soluções urbanas de melhoria da mobilidade, objetivando a construção de um modelo espacial com a finalidade de promover a sustentabilidade socioambiental e econômica, reafirmando a Capital como metrópole regional. Para isso devem-se buscar financiamentos e parcerias, onde o município, isoladamente ou em consórcio com os municípios da mesma região, obtenha contratos e convênios com entidades estatais, paraestatais e autarquias particulares, concessionárias ou permissionárias de serviços de utilidade pública. Para tanto, é importante investir inicialmente em relação à capacitação de seus gestores. Também promover e incentivar a integração entre os diversos setores e secretarias da Prefeitura, potencializando uma gestão mais centrada nos objetivos e mais consistente, para a obtenção de resultados, observando principalmente os indicadores com valores desfavoráveis.

No quesito referente aos investimentos em Goiânia, mais recentemente as empresas de transporte estão principiando uma modalidade nova de captação de recursos para investimentos em infraestrutura e tecnologia: os Fundos de Investimento em Diretos Creditórios (FIDC), também conhecidos como fundos de recebíveis. Esses papéis são lançados no mercado financeiro com a única garantia de retorno e remuneração do capital, baseada na arrecadação do sistema de transporte local.

Entretanto, a dependência da população sobre os modos motorizados, sobretudo e principalmente do automóvel particular, é um dos pontos que influi negativamente na mobilidade das cidades, assim como a falta de incentivo, por exemplo, para o uso da bicicleta como modo cotidiano e regular de transporte. Portanto, mesmo que os planos contemplaram e continuem com diretrizes condizentes com as boas propostas e soluções de regulamentação, para ações no urbano com transporte público eficiente e de qualidade, é indispensável, inclusive para que seja de maneira continuada, que se tenham uma boa estrutura e gerenciamento, ou seja, políticas comprometidas com o desenvolvimento sustentável. Outro agravante é que, 
na grande maioria das vezes, os Planos não são totalmente implantados, ou são revisados de maneira não tão favoravelmente à resolução dos problemas de mobilidade.

Desse modo, a melhoria do transporte público influi sobremaneira na Mobilidade Urbana Sustentável a qual, para efetivar uma gestão composta de outros modais integrados ao transporte coletivo como a bicicleta, assim como o incentivo de outras práticas não motorizadas, é necessário que se busque soluções com parceria entre o poder público e a iniciativa privada. Para que assim seja concretizada com sucesso, colocando-a em prática com uma implementação espacial adequada. Necessário e primordial também que se tenha um desenvolvimento a contento do transporte coletivo em consonância com o Plano Diretor geral, com o Plano Diretor de Transportes e também com o Plano de Mobilidade, para que haja uma maior e melhor mobilidade, satisfatória e sustentável.

Para tanto, agenciar a conjugação de esforços, a assistência técnica e financeira, a troca de informações e a coordenação de atividades e recursos para atingir os objetivos do planejamento. Utilizar os indicadores para que visualize as deficiências e busque soluções para minimizar os pontos mais deficitários. Isso para as devidas adequações e correções do já edificado e a exigência do cumprimento das leis nas construções das edificações, vias, calçadas, etc., evitando, ainda, a continuidade das práticas danosas à mobilidade e acessibilidade de toda a população. É um trabalho que deverá ser contínuo e envolver a sociedade como um todo e é responsabilidade de toda a sociedade e de todas as administrações.

\section{Considerações finais}

Com o método do Imus, reconhecem-se as características dos vários indicadores calculados, e verificam-se as deficiências, facilitando a adoção de medidas de controle e prevenção. Portanto, com os resultados dos indicadores encontrados para Goiânia, mostrou-se que com o índice calculado de 0,659, e as intervenções necessárias, são capazes de serem melhorados com o uso de políticas, metas e ações adequadas. Para a realização dessas metas é de suma importância facilitar o acesso a recursos financeiros para capacitação e assistência técnica, assim como para a implantação das ações e projetos de maneira democrática e sustentável. Com ações e interferências acertadas, permite-se que a utilização do índice seja para a formulação de políticas integradas e direcionadas à mobilidade, beneficiando, assim, a uma aplicação mais racional e eficiente de recursos.

Quanto às sugestões referentes ao resultado da aplicação do Imus juntamente com os indicadores que contribuíram na composição de seu cálculo, propõe-se a observância e monitoração dos indicadores, a fim de que os escores baixos tenham respaldo junto aos órgãos responsáveis pelo planejamento para ações de monitoração e melhoria. Também que os indicadores com grau satisfatório sejam citados como exemplo e, em conjunto aos demais, possa haver maior interação. Igualmente contribuir para a Mobilidade Urbana Sustentável e, consequentemente, para a sustentabilidade da cidade e qualidade de vida de toda a população. 
Espera-se que a proposta contida neste trabalho possa estimular a aplicação do Imus de forma a ampliar o seu entendimento e detaIhamento em estudos futuros, como por exemplo, concretizar o cálculo do Imus nas cidades que compõe a região metropolitana, para assim, ter-se diagnóstico mais preciso, principalmente pelo transporte coletivo de Goiânia envolver toda a região metropolitana.

Além de propostas para o Imus, podem ser definidas alternativas eficazes que utilizem outros modos de transportes e novos hábitos como, por exemplo, incentivar a utilização de bicicletas e o modo a pé para prevenir problemas mais graves, e para que ocorram mudanças de fato é preciso convencer técnicos e gestores, assim como a população em geral. Nesse sentido, é interessante visualizar os possíveis resultados das várias alternativas de atuação propostas, como medidas de incentivo a viagens sustentáveis através da integração modal, e a instalação de estacionamento junto a terminais intermodais de transporte como bicicletários e estacionamento de carros. Também a integração tarifária e a taxa de viagens sustentáveis, onde a primeira já é praticada em Goiânia assim como já há bicicletários implantados e outros estão sendo implantados ou previstos.

Dentre os estudos propostos, é sugerido que pode ser feito através da construção de cenários como o proposto por Mancini (2011), onde um conjunto de possíveis ações de planejamento urbano e de transporte, escolhidos dentre os indicadores do Imus, possa se avaliar a cidade quanto à mobilidade urbana sustentável e aplicar as medidas necessárias. Esse trabalho deverá ser realizado através de gestores em conjunto com técnicos e a sociedade, projetando as melhores alternativas para se atingir as metas propostas.

Os estudos e cálculo do Imus, nas várias cidades, assim como também outros estudos como o de Mancini (2011) e o de Azevedo FiIho (2012), propõem ações de planejamento urbano e de transporte e também análise do processo de planejamento dos transportes, sugerindo estudos de contribuição para o aperfeiçoamento do Imus.

\section{Ivanilde Maria de Rezende Abdala}

Prefeitura de Goiânia, Secretaria de Desenvolvimento Urbano Sustentável - Semdus, Obras e Urbanismo. Goiânia/GO, Brasil.

ivanildera@gmail.com

\section{Antônio Pasqualetto}

Pontifícia Universidade Católica de Goiás, Instituto Federal de Educação, Ciência e Tecnologia de Goiás. Goiânia/GO, Brasil.

pasqualetto@pucgoias.edu.br 


\section{Referências}

ABNT (2004). NBR 9050 - Acessibilidade a edificações, mobiliário, espaços e equipamentos urbanos. Rio de Janeiro. Associação Brasileira de Normas Técnicas.

AGUIAR, F. de O. (2010). Acessibilidade relativa dos espaços urbanos para pedestres com restrição de mobilidade. Tese de doutorado. São Carlos, Universidade de São Paulo. Disponível em: http:// www.teses.usp.br/teses/disponiveis/18/18144/tde-21042010-193924/pt-br.php. Acesso em: $18 / 5 / 2011$.

AZEVEDO FILHO, M. A. N. D. (2012). Análise do processo de planejamento dos transportes como contribuição para a mobilidade urbana sustentável. Tese de doutorado. São Carlos, Universidade de São Paulo.

BOARETO, R. (2008). A política de mobilidade urbana e a construção de cidades sustentáveis. Revista dos Transportes Públicos - ANTP, ano 30/31, pp. 143-160.

BRASIL (2006). Mobilidade e desenvolvimento urbano. Brasília, Ministério das Cidades. (Gestão integrada da mobilidade urbana, 2).

(2012). Lei de diretrizes da política nacional de mobilidade Urbana. Lei no 12.587. Brasília. Disponível em: www.planalto.gov.br/ccivil_03/_ato2011-2014/2012/lei/l12587.html. Acesso em: 3 fev 2012.

BRASIL ACESSÍVEL (2006). Programa brasileiro de acessibilidade urbana. Brasília, Ministérios das Cidades.

CENTRO DE GESTÃO E ESTUDOS ESTRATÉGICOS - CGE (2009). P\&D/Estudo 1: redes nacionais e internacionais de P\&D em mobilidade urbana e seus indicadores. Relatório técnico. In: Estudo prospectivo mobilidade urbana. Brasília, Centro de Gestão e Estudos Estratégicos.

COSTA, M. S. (2008). Um índice de mobilidade urbana sustentável. Tese de doutorado, São Carlos, Universidade de São Paulo.

COSTA, M. S.; RAMOS, R. A. R. e SILVA, A. N. R. (2007). Índice de mobilidade urbana sustentável para cidades brasileiras. In: XXI ANPET - PANORAMA NACIONAL DA PESQUISA EM TRANSPORTES. Anais. Rio de Janeiro, ANPET.

DA ASSUNÇÃO, M. A. (2012). Indicadores de mobilidade urbana sustentável para a cidade de Uberlândia, MG. Dissertação de mestrado. Uberlândia, Universidade Federal de Uberlândia.

DOMINGUES, C. V. (2005). Aplicação de geoprocessamento no processo de modernização da gestão municipal. Dissertação de mestrado. Campinas, Universidade Estadual de Campinas.

GOIÂNIA (1992). Plano de Desenvolvimento Integrado de Goiânia (PDIG 2000). Goiânia, Instituto de Planejamento Municipal da Prefeitura Municipal de Goiânia, pp. 1-86.

GOIÂNIA, Prefeitura Municipal (2007). Lei Complementar № 171. Plano diretor do município de Goiânia. Goiânia, Secretaria Municipal de Planejamento e Urbanismo.

GUDMUNDSSON, H. (2011). Indicators of environmentally sustainable transport' - why, watt and how to measure? Yokohama, United Nations University, pp. 1-32. Disponível em: www. globalsustainability.org/data/ACF205.pdf. Acesso em: 5 maio 2011. 
LOPES, S. B. (2010). Uma ferramenta para planejamento da mobilidade sustentável com base em modelo de uso do solo e de transportes. Tese de doutorado. São Carlos, Universidade de São Paulo.

MACÊDO, M. H.; SILVA, A. N. e COSTA, M. S. (2006). Abordagem sistêmica da mobilidade urbana: reflexões sobre o conceito e suas implicações. São Paulo, Pluris, pp. 1-13.

MACÊDO, M. H.; ABDALA, I. M. R. e SORRATINI, J. A. (2012). Uma contribuição ao cálculo do indicador de acessibilidade do índice de mobilidade urbana sustentável. In: XXVI ANPET. Anais. Joinville, Anpet, pp. 1768-1779.

MACHADO, L. (2010). Índice de mobilidade sustentável para avaliar a qualidade de vida urbana Estudo de caso: Região Metropolitana de Porto Alegre - RMPA. Dissertação de mestrado. Porto Alegre, Universidade Federal do Rio Grande do Sul.

MAGAGNIN, R. C. (2008). Um sistema de suporte à decisão na internet para o planejamento da mobilidade urbana. Tese de doutorado. São Carlos, Universidade de São Paulo.

MAGAGNIN, R. C. e RODRIGUES DA SILVA, A. N. (2008). A percepção do especialista sobre o tema mobilidade urbana. Revista Transportes. São Paulo, v. XVI, n. 1, pp. 25-35.

MANCINI, M. T. (2011). Planejamento urbano baseado em cenários de mobilidade sustentável. Dissertação de mestrado. São Carlos, Universidade de São Paulo.

MIRANDA, H. de F. (2010). Mobilidade urbana sustentável e o caso de Curitiba. Dissertação de mestrado. São Carlos, Universidade de São Paulo.

MORAIS, T. C. (2012). Avaliação e seleção de alternativas para promoção da mobilidade urbana sustentável - o caso de Anápolis. Dissertação de mestrado. São Carlos, Universidade de São Paulo.

PLAZA, C. V. e RODRIGUES DA SILVA A. N. (2010). Elementos para promoção de mobilidade urbana sustentável em uma cidade média brasileira. In: XIV CONGRESSO DA ASSOCIAÇÃO CODATU (Coopération pour le Développement et l'Amélioration des Transports Urbains et périurbains). Anais. Buenos Aires, Associação Codatu.

RODRIGUES DA SILVA, A. N.; COSTA, M. S. e MACÊDO, M. H. (2008). Multiple views of sustainable urban mobility - the case of Brazil. Transport Policy, v. 15, n. 6, pp. 350-360.

Texto recebido em 20/mar/2013

Texto aprovado em 5/maio/2013 
